\title{
REENHEBRANDO EL PASADO: HACIA UNA EPISTEMOLOGÍA DE LA MATERIALIDAD
}

\section{RETHREADING THE PAST: TOWARDS AN EPISTEMOLOGY OF MATERIALITY}

\author{
FÉlIX A. ACUTO*, MARINA SMITH** \\ EZEQUIEL GILARDENGHI***
}

Este artículo busca discutir a nivel epistemológico la manera en que deberíamos comenzar a romper las barreras que los dominios materiales construidos por la arqueología (tales como cerámica, lítico, textil, arte rupestre, etc.) imponen a nuestra interpretación, para empezar a reconstruir la materialidad del pasado, entendida esta como las articulaciones que se producían en las sociedades pasadas entre lugares, objetos, representaciones gráficas, personas, prácticas y esferas sociales y de experiencia. Para llevar adelante esta discusión se desarrollará el ejemplo del Período Intermedio Tardío (1000-1450 DC) en el valle Calchaquí Norte (Noroeste Argentino), siguiendo la trayectoria de las representaciones visuales plasmadas en vasijas cerámicas y aquellas inscritas sobre rocas, para reconstruir las relaciones con otros objetos y lugares, así como las experiencias subjetivas, las prácticas y las relaciones sociales con las que vasijas y rocas grabadas, y sus representaciones, estaban articuladas.

Palabras clave: materialidad, enhebrar, representaciones, lugares, interacciones, experiencias

This paper offers an epistemological discussion of how we can begin to break away from the constraints that the material domains built by archaeology (ceramic, lithic, textile, rock art, etc.) impose upon our interpretations and begin to reconstruct the materiality of the past, understood here as the articulations produced in past societies among places, objects, graphic representations, persons, practices and spheres of social interaction and experience. In doing so we examine the North Calchaqui Valley of Northwestern Argentina in the Late Intermediate Period (1000-1450 AD), following the trajectories of the visual representations painted on ceramic vessels and carved on rocks to reconstruct their relation to other objects and places, as well as to the subjective experiences, practices and social relationships with which they were articulated.

Key words: materiality, threading, representations, places, interactions, experiences

\section{INTRODUCCIÓN}

Este artículo busca discutir a nivel epistemológico, y valiéndonos de un ejemplo, la manera en que deberíamos comenzar a romper las barreras que nos imponen los dominios materiales construidos por la arqueología para empezar a reconstruir las articulaciones que se producían en las sociedades pasadas entre objetos, lugares, representaciones visuales, significados, personas, prácticas y esferas sociales y de experiencia.

Tanto las arqueologías histórico-culturales como las procesuales nos han acostumbrado a pensar el pasado en términos de categorías de artefactos, por ejemplo: lítico, cerámica, objetos de metal, representaciones rupestres, textiles, etc. Estas categorías se conformaron como campos de saber independientes y cuentan, en cada caso, con un vasto corpus teórico, así como variados métodos (desde diferentes técnicas de análisis hasta aproximaciones actualísticas y experimentales). Como consecuencia de esto, cada tipo de artefacto ha sido tratado de manera separada y desconectada de los otros tipos, tanto en el laboratorio, como en la teoría y en la interpretación.

Este modo de construir la práctica arqueológica, de establecer el entrenamiento de estudiantes (a quienes se asigna un tipo de artefacto como tema de investigación), de producir teoría y de organizar el laboratorio,

* Félix A. Acuto, ImHicinu-Conicet, Saavedra 15, Piso 5, C1083ACA, Buenos Aires, email: facuto@gmail.com

* Marina Smith, Departamento de Antropología, Facultad de Filosofía y Letras, Universidad de Buenos Aires, email: marinitasmith@hotmail.com

*** Ezequiel Gilardenghi, Departamento de Antropología, Facultad de Filosofía y Letras, Universidad de Buenos Aires, email: bubalev@hotmail.com 
ha llevado a olvidar que lo que estudia la arqueología no es una categoría de objetos por sí misma, sino la vida social en el pasado. Y por supuesto, dicha vida social no estuvo construida, y no está representada, por los instrumentos de piedra, las ollas, los huesos de animales o los textiles aisladamente.

Sumado a esto, se ha asumido, por lo general implícitamente, que nuestras compartimentalizaciones analíticas y prácticas fueron también significativas para las sociedades pasadas que estudiamos. Es decir, se ha supuesto que las sociedades pasadas reconocían en las vasijas cerámicas, los artefactos líticos o el arte rupestre, categorías independientes y mutuamente excluyentes. Relacionado con esto, también se ha asumido que la producción y el uso de cada tipo de objeto constituyó, en todo tiempo y lugar, una esfera de prácticas y relaciones sociales discretas e independientes (este puede ser el caso para ciertas sociedades y no para otras). Por ejemplo, la obtención de materia prima lítica, la manufactura de instrumentos de piedra y su uso se han planteado como parte de un sistema coherente y articulado de comportamientos funcionales que parecerían no interceptarse con otras prácticas, representaciones y objetos, como por ejemplo la semantización del paisaje, la articulación de redes de sociabilidad o de poder, la constitución de géneros y corporeidades, o la producción de otros artefactos.

La etnografía nos ha enseñado que la dinámica social en sociedades no occidentales no ocurre en subsistemas independientes caracterizados por ciertos comportamientos funcionales y determinadas herramientas adecuadas para alcanzar fines específicos. Por el contrario, la vida social implica una red de relaciones intersubjetivas y materiales articuladas, y no compartimentos estancos y desconectados. En este sentido, esferas sociales y sistemas de objetos disímiles y disociados en nuestra cosmovisión y experiencia moderna, tal como la vida cotidiana y la muerte, la casa y el cosmos, o la crianza de niños, el crecimiento de plantas y la producción de ciertos artefactos pueden estar ontológica y lingüísticamente vinculados en otras sociedades (véase Allen 1988; Strathern 1988; Battaglia 1990; Arnold et al. 1992; Gell 1995; Ingold 2000, entre otros). Por lo tanto, se puede sostener que la arqueología ha tendido a imponer sus propias clasificaciones al pasado (clasificaciones funcionalistas y tipológicas típicas del pensamiento moderno) (Thomas 2004), rompiendo los vínculos que los artefactos tenían entre sí y con las personas, así como también deshilvanándolos de las relaciones sociales y esferas de experiencias (cotidiana, ritual, mortuoria, política, de relaciones de género, etc.) con las que se encontraban articulados.
Teniendo en cuenta estas ideas, por materialidad no entendemos categorías específicas de artefactos, tal como la conciben algunos arqueólogos en la actualidad (materialidad cerámica, materialidad lítica, materialidad textil, materialidad arquitectónica, etc.), dándole un fino barniz de contemporaneidad teórica a una vieja manera de abordar el pasado, sino que nos referimos a un orden material históricamente producido y dentro del cual se constituye una vida social particular (Miller 1987, 2005). Se trata de una red de objetos interconectados que adquieren una configuración espacio-temporal específica y que se articulan dialécticamente con prácticas, relaciones sociales, significados y cosmologías determinadas. Al decir dialécticamente nos referimos a que este orden material: 1) es constituido por y constituyente de dichas relaciones, prácticas y cosmologías, y 2) es un aspecto integral de estas prácticas, interacciones y experiencias, y su transformación implicaría necesariamente la modificación de estas últimas.

El objetivo de la arqueología debería ser reenhebrar la materialidad de casos históricos particulares usando como hilo conector las relaciones sociales, las prácticas y las experiencias. Esta metáfora no es azarosa. Al tejer se busca formar una trama continua. Si bien por cuestiones operativas podemos analizar la evidencia material por separado, una epistemología arqueológica que busca dar cuenta de la materialidad del pasado debe realizar este paso de enhebración en el cual, en la trama final, se diluyen las separaciones analíticas para comenzar a emerger la naturaleza de la vida social del pasado. En este tejido, que son las narrativas que producimos sobre el pasado, las categorías arqueológicas se disuelven y reconstituyen para dejar a la interpretación en primer plano. En esta manera de producir conocimiento sobre el pasado por medio del estudio de la materialidad, las representaciones visuales no deberían ser analizadas aisladamente, sino que tienen que ser rearticuladas con el orden material al que pertenecían, reconectando no solo a los objetos (y las representaciones que llevaban inscritas) entre sí, sino también a estos con las relaciones intersubjetivas, las experiencias, las prácticas sociales, los sentidos y los espacios con los que estaban enlazados, así también con los que no lo estaban.

Para llevar adelante esta discusión se desarrollará a continuación el ejemplo del Período Intermedio Tardío (1000-1450 DC) en el valle Calchaquí Norte (Noroeste Argentino) (fig. 1), siguiéndose la trayectoria de las representaciones visuales plasmadas en vasijas cerámicas y aquellas inscritas sobre rocas para reconstruir las relaciones con otros objetos y las experiencias subjetivas, prácticas, interacciones y espacios con las que vasijas y petroglifos, y sus representaciones, estaban articuladas. ${ }^{1}$ 


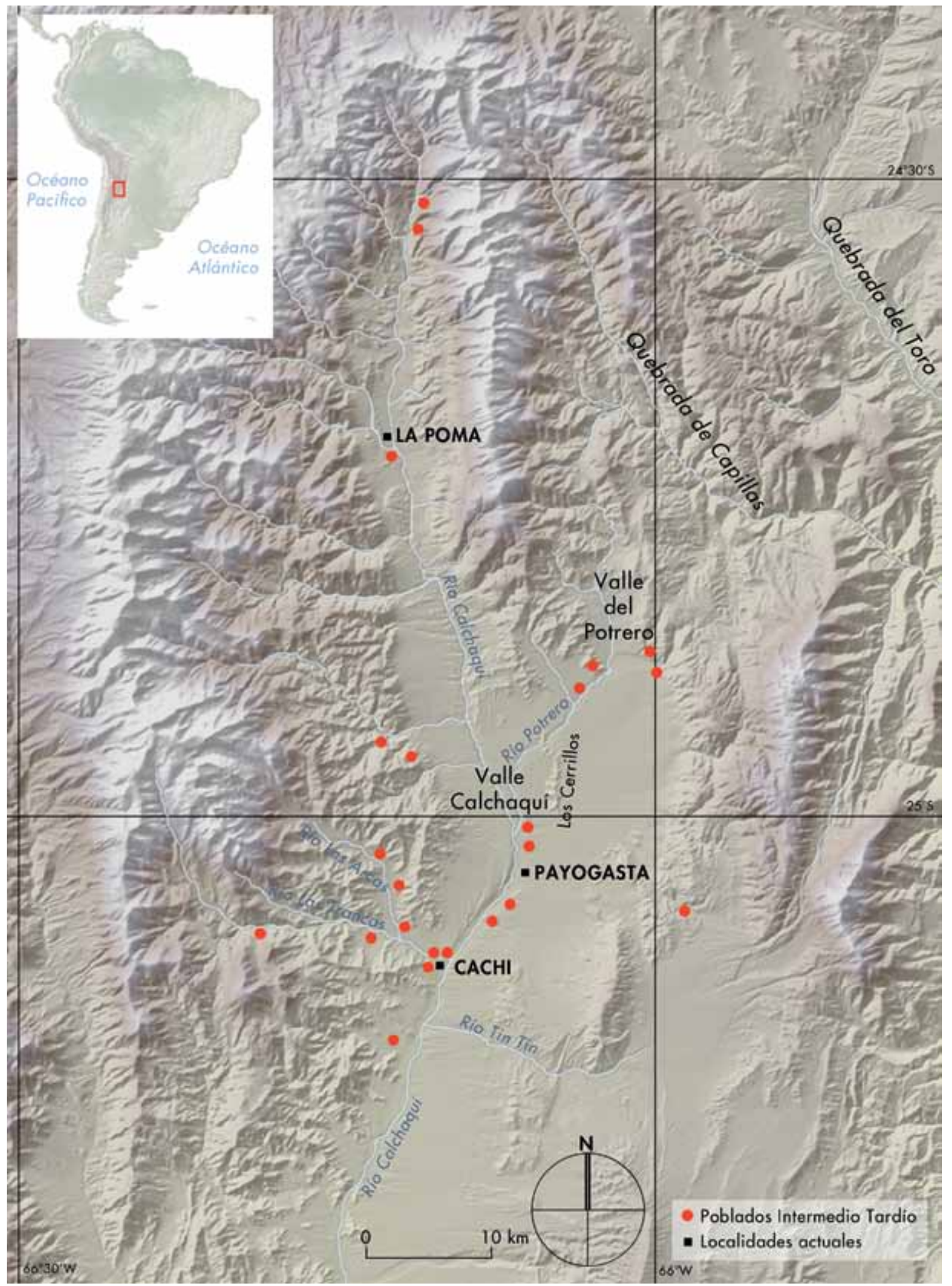

Figura 1. Valle Calchaquí Norte (Salta, Argentina).

Figure 1. Northern Calchaquí Valley (Salta, Argentina). 
De este modo podremos entender el contexto dentro del cual las representaciones interactuaban, así como también alcanzar cierto nivel de comprensión sobre sus significados.

\section{LA TRAMA DEL PASADO: LUGARES, OBJETOS, REPRESENTACIONES VISUALES'E INTERACCIONES}

Podemos empezar este análisis diciendo que la espacialidad es la matriz que une y da lógica a la vida social y al orden material. En nuestro caso de estudio, el paisaje del Período Intermedio Tardío en el valle Calchaquí Norte estaba conformado por una serie de lugares con un orden material específico y que creaban esferas particulares de experiencias, interacciones y significados. Estos lugares donde transcurría la vida social de esta época fueron: grandes poblados conglomerados, asentamientos satélites más pequeños, áreas de producción agrícola, pequeños puestos de pastoreo, algunos sitios defensivos y sitios que concentraban petroglifos, entre los más importantes.

En este entramado espacial, los sitios habitacionales y los sitios de petroglifos conformaron esferas de sociabilidad, experiencias y representaciones separadas y marcadamente diferenciadas. No solo se trataba de lugares espacialmente alienados (a pesar de la disponibilidad de rocas potencialmente grabables, muy raramente se encuentran representaciones sobre piedra dentro de los poblados habitacionales, como tampoco se las encuentra en sitios pequeños, establecimientos defensivos o áreas agrícolas), sino que también, y como se verá más adelante, varias de las representaciones visuales que participaban de la vida diaria de los poblados (en vasijas cerámicas, artefactos de metal y torteros) diferían marcadamente de aquellas plasmadas sobre las rocas. ${ }^{2}$ En este punto es importante destacar que los sitios de arte rupestre tienen lugar tanto en afloramientos rocosos fijos como en puntos particulares del paisaje donde un número de rocas medianas con grabados - que van desde cinco a más de trescientos- o para ser grabadas in situ, fueron transportadas y concentradas.

Pasemos entonces a describir estos dos tipos de lugares, su materialidad y espacialidad, su sentido de lugar y la naturaleza de las interacciones sociales que allí se producían.

Los poblados principales durante el Período Intermedio Tardío del valle Calchaquí Norte se caracterizaban por ser conglomerados de entre 200 y 500 estructuras semisubterráneas y contiguas que configuraban un patrón celular, con los complejos residenciales como su unidad básica. Es interesante que gran parte de la vida social de la época transcurría en estas localidades. Era allí donde tenían lugar y se articulaban un número importante de prácticas y esferas sociales: vida doméstica y cotidiana, actividades públicas de agregación comunitaria, prácticas funerarias, rituales domésticos, almacenaje, relación personas/animales domésticos, socialización, reproducción biológica, crianza, producción simbólica y la manufactura y consumo de una gran cantidad de artefactos (vasijas cerámicas, artefactos de piedra, textiles y metalurgia, instrumentos para la producción agrícola, entre los más importantes) (Acuto et al. 2008).

A partir del análisis detallado de la arquitectura y la organización espacial de este tipo de sitios, así como de la evidencia de superficie y aquella obtenida por diversas excavaciones, hemos argumentado que tres experiencias y sentidos eran vivenciados en dichos lugares: 1) articulación, permeabilidad y apertura, 2) redundancia y homogeneidad material, y 3) sentido de compartir (ver Acuto 2007; Acuto et al. 2008). Para este artículo discutiremos brevemente los dos primeros aspectos.

Estos asentamientos conformaban un continuo de arquitectura conectada por puertas y una amplia red de senderos sobreelevados y muros/senderos que alcanzaban prácticamente cada rincón del poblado. No había áreas espacial, arquitectónica o topográficamente separadas, diferenciadas y de acceso restringido, sino que estos lugares se conformaron como un todo unificado. Así, la manera en que los edificios estaban emplazados -junto con el modo en que la circulación estaba diseñada- no generaban fragmentación, sino que en la práctica contribuían con la integración de sus residentes, facilitando sus interacciones cotidianas. Sumado a esto, y teniendo en cuenta que la arquitectura era semisubterránea, que las vías de circulación interna se encontraban sobreelevadas con respecto a los pisos de ocupación y que aproximadamente entre un $85 \%$ y un $90 \%$ de los edificios dentro de estos lugares eran patios sin techar (Gifford 2003), loci de la gran mayoría de las actividades que se realizaban en estos asentamientos (desde procesamiento y cocción de alimentos hasta producción de artefactos) (Díaz 1978-1984, 1981), podemos sostener entonces que además de la gran accesibilidad física que ofrecía la amplia red de senderos dentro de los sitios existió también una gran accesibilidad visual que permitió, al circular, conocer qué sucedía en la comunidad propia.

Estos poblados principales no contaban con edificios administrativos, estructuras monumentales, concentraciones de almacenes o plazas centrales y únicas que representasen un poder político centralizado y manifestasen desigualdad social. Por el contrario, estos grandes asentamientos conglomerados estaban compuestos por 
varios clusters de estructuras residenciales articuladas entre sí y demarcados y separados por los senderos sobreelevados. No existían diferencias destacadas entre cada uno de estos conjuntos residenciales en cuanto a su arquitectura, los bienes producidos y consumidos y las actividades realizadas. Quienes vivían en estos clusters empleaban los mismos tipos de objetos y tenían sus propios espacios de congregación y sus propios almacenes. Así, la materialidad de los asentamientos conglomerados, donde cada cluster de estructuras era el reflejo material del otro, configuraba una vida social que evitaba la distinción y la estratificación y afirmaba la semejanza.

Era en estos grandes asentamientos conglomerados el lugar donde la cerámica decorada de estilo santamariano fue manufacturada al interior de las residencias. Por las evidencias que tenemos hasta ahora, esta cerámica no era producto de la labor de especialistas sino del trabajo doméstico. Se trata de un bien material característico de la vida social dentro de los poblados, siendo nula o prácticamente nula su presencia en los otros tipos de sitios del período. En este sentido, su iconografía (que como se verá a continuación era acentuadamente distinta a la plasmada sobre roca) conformaba parte de un imaginario que estaba relacionado con la vida cotidiana. Sumado a esto, dichas vasijas constituían uno de los objetos más abundantes y ubicuos de la cultura material de los poblados (Acuto et al. 2008). Su distribución dentro de estos lugares fue amplia y homogénea. Cada unidad doméstica poseía y empleaba cerámica decorada, por lo que podemos inferir que no se trataba de un bien de prestigio de acceso restringido. Las vasijas decoradas aparecen dentro de las casas, relacionadas con actividades simples y cotidianas (cocinar, almacenar, servir alimentos), y depositadas como ofrendas en tumbas de adultos y niños, o como urnas de infantes. En este último caso, es importante aclarar que las tumbas de adultos y niños eran parte de la esfera cotidiana vivida al interior de los poblados conglomerados (Amuedo 2010; Acuto et al. 2011).

La cerámica decorada parece haber compartido y reforzado los principios estructurantes que la espacialidad y el orden material de los poblados creaban. ${ }^{3}$ Nuestros análisis sobre la decoración de las vasijas se realizaron en 122 piezas provenientes de distintos sitios, y distintos contextos dentro de un mismo sitio, depositadas en el Museo Arqueológico Pío Pablo Díaz (Cachi, Salta). ${ }^{4}$ Hasta el momento se estudiaron 53 ollas de cuellos alargados, comúnmente denominadas urnas (las cuales se dividen en urnas comunes y urnas de tres cinturas), y 69 bowls o pucos. ${ }^{5}$ Es importante destacar que urnas y pucos son las formas más populares del repertorio cerámico decorado del valle Calchaquí Norte, conformando un $85 \%$ de la alfarería decorada de esta época.

Hemos comprobado que el modo como la decoración está organizada en las piezas exhibe una consistencia muy marcada tendiente a la dualidad y la simetría. En el caso de la decoración externa de las urnas, esta se realizó a partir de dos ejes verticales (o guardas) que pasan por las asas y dividen a la vasija en dos frentes. Exceptuando el análisis de 23 piezas muy erosionadas y/o fragmentadas, en el resto se comprobó que las caras A y B de las vasijas eran simétricas en cuanto a la presencia y la ubicación de los motivos principales (aquellos de mayor tamaño, mayor visualización y que refieren al "tema" principal a representar) en el 97\% de los casos (29 urnas decoradas) (figs. 2 y 3), habiéndose reconocido hasta el momento tan solo una urna $(3,3 \%)$ en la cual no estaba presente este patrón.

Por su parte, la estructura del diseño, o la manera en que los motivos estaban distribuidos en cada una de las caras de las urnas, también muestra un patrón
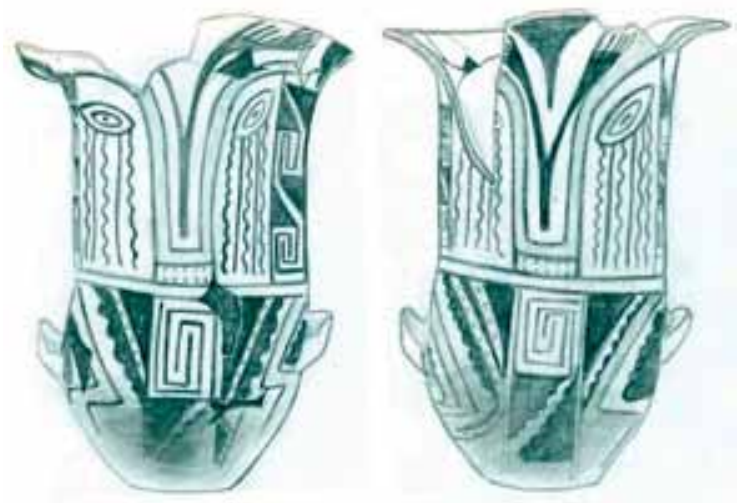

Figura 2. Caras A y B de la Pieza N 4332. Procedencia: sitio Tero (SSalCac 14). Dibujo de Marina Smith.

Figure 2. Faces $A$ and $B$ of Piece 4332. Origin: Tero site (SSalCac 14). Drawing by Marina Smith.
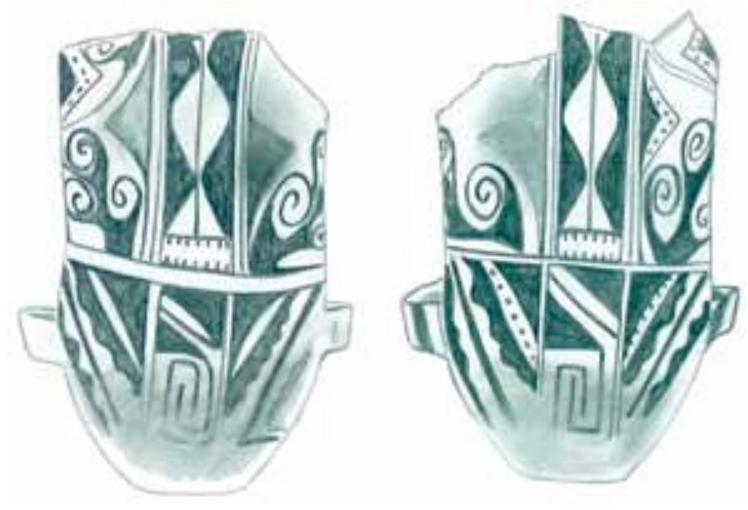

Figura 3. Caras A y B de la Pieza $N^{\circ}$ 142. Procedencia: sitio Loma del Oratorio (SSalCac 8). Dibujo de Marina Smith.

Figure 3. Faces $A$ and $B$ of Piece 142. Origin: Loma del Oratorio site (SSalCac 8). Drawing by Marina Smith. 
caracterizado por principios de dualidad y simetría (reflexión de tipo espejo). En el caso de las urnas comunes $(\mathrm{n}=44$, de las cuales, y por cuestiones de conservación de la decoración, solo 39 pudieron ser analizadas), estas presentan un patrón de diseño vertical caracterizado por un eje central (en varios casos formado por una guarda vertical) que divide a la pieza en dos mitades (fig. 4). El análisis mostró que en la totalidad de las urnas comunes la decoración principal del lado derecho se reflejaba en el lado izquierdo. El caso de las urnas de tres cinturas es diferente, ya que su patrón decorativo suele ser horizontal y no poseen un eje central. No obstante, de las nueve urnas de tres cinturas presentes en la muestra, cinco presentaban una decoración vertical en el cuello con un eje central y lados que se reflejan.

Del total de pucos estudiados, por temas de preservación solo en 38 casos pudo determinarse certeramente el tipo de estructura decorativa. La decoración externa de todos estos pucos fue organizada a partir de una división dual por una guarda que cruza la superficie de la vasija a la altura de las asas (fig. 5). En 35 de estos casos (92\%) pudo constatarse una estructura decorativa simétrica, en la cual la presencia y la ubicación de los motivos representados en los campos decorativos de una mitad se reflejan en los de la otra mitad. En las restantes tres piezas (8\%) se comprobó una simetría alterna, al repetir el repertorio de motivos pero variando su ubicación: el motivo que de un lado aparecía en el área del borde, en el otro lado aparecía en la zona del cuerpo (ver fig. 5, segundo ejemplo).

Es interesante notar que si bien es evidente que dualidad y simetría conformaron un patrón redundante en la organización de la decoración principal de las vasijas más representativas y ubicuas de la vida cotidiana norcalchaquí, en algunos casos existió también cierto nivel de asimetría en los motivos empleados como relleno, en los detalles de los motivos principales o en el tamaño de motivos principales o rellenos (ver figs. 2 y 3). Por tratarse de una producción artesanal es esperable cierto nivel de variación producto de la misma práctica, y la pericia y agencia de los artesanos. Sin embargo, la muestra analizada no refleja acciones estratégicas y sistemáticas tendientes a romper con la asentada tradición decorativa y sus principios de dualidad y simetría. Hasta
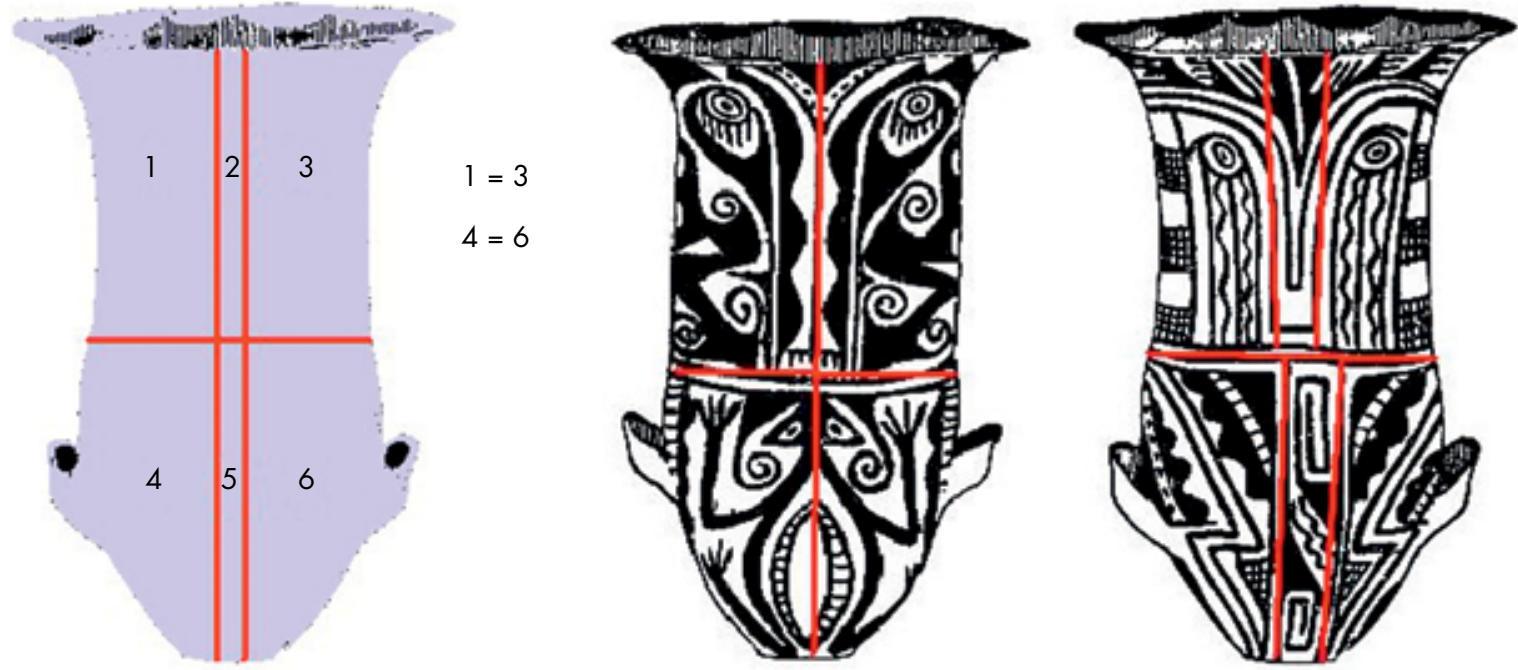

Figura 4. Estructura del diseño de urnas (redibujadas de Ambrosetti 1907-1908).

Figure 4. Urn design structure (redrawn from Ambrosetti 1907-1908).
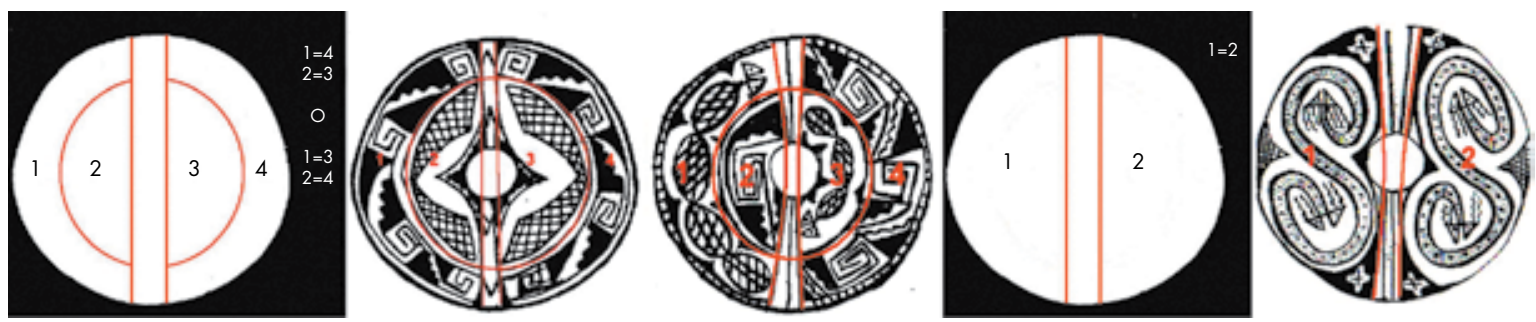

Figura 5. Estructura del diseño de pucos (redibujados de Ambrosetti 1907-1908).

Figure 5. Bowl design structure (redrawn from Ambrosetti 1907-1908). 
el momento hemos detectado unos pocos casos que muestran cierta transformación del patrón de simetría, aunque lejos están de representar un abandono total de la tradición. Estos son una urna que, manteniendo su organización dual de la decoración, presenta uno de sus motivos en asimetría, y cuatro pucos publicados en Ambrosetti (1907-1908: 338, 343, 344 y 353) con simetría parcial.

En relación con la iconografía, se ha observado que el repertorio de motivos empleados para decorar las vasijas fue reducido y altamente redundante. Para el análisis, se contabilizaron las composiciones de motivos visibles en las piezas estudiadas. En el caso de una guarda de grecas, por ejemplo, entendemos no cada greca individual sino la guarda completa, la cual sería contabilizada como una. En este caso, consideramos los motivos principales y no los elementos empleados como relleno de los espacios entre los motivos principales. De las 122 piezas analizadas se registraron 546 composiciones de motivos principales, los cuales fueron divididos en 12 tipos (Tabla 1, fig. 6). Dentro de este universo, cuatro fueron los dibujos más populares (grecas, lineales, espirales y serpentiformes), representando el $70 \%$ de la muestra, y alcanzándose casi el $90 \%$ si se agregan a este conjunto los rostros y los chevrones (fig. 7). En pocas palabras, la gran mayoría de la decoración de las vasijas se llevó a cabo a partir del uso de seis motivos. En este punto es interesante notar que hemos detectado una muy baja proporción $(0,73 \%)$ de motivos únicos y no repetidos.

Tabla 1. Tipos de motivos presentes en la cerámica analizada: cantidad y porcentaje.

Table 1. Quantity and percentage of motif types present in the ceramics analyzed.

\begin{tabular}{|l|c|c|}
\hline \multicolumn{1}{|c|}{ Motivos } & Cantidad & $\%$ \\
\hline 1. Greca & 123 & 22,53 \\
\hline 2. Lineal & 99 & 18,13 \\
\hline 3. Espiral & 88 & 16,12 \\
\hline 4. Serpentiforme & 72 & 13,19 \\
\hline 5. Rostro & 51 & 9,34 \\
\hline 6. Chevrón & 44 & 8,06 \\
\hline 7. Manos & 19 & 3,48 \\
\hline 8. Batraciomorfo & 17 & 3,11 \\
\hline 9. Ornitomorfo & 15 & 2,75 \\
\hline 10. Damero & 8 & 1,46 \\
\hline 11. Reticulado & 6 & 1,1 \\
\hline 12. Otros & 4 & 0,73 \\
\hline Total & 546 & 100 \\
\hline
\end{tabular}

La popularidad de estos seis elementos decorativos se verifica cuando analizamos la ubicuidad que estos tuvieron. El conjunto formado por los primeros cuatro motivos alcanza una ubicuidad del 75,4\%; es decir, están presentes en más del $70 \%$ del total de las piezas estudiadas. Por su parte, el conjunto formado por los anteriores más los rostros y los chevrones presenta una ubicuidad de $100 \%$.

Si tenemos en cuenta los datos hasta aquí discutidos (el reducido número de motivos empleados para decorar las vasijas cerámicas, su alta ubicuidad y la difundida estructura del diseño), y consideramos que las 122 piezas analizadas provienen de distintos sitios, y de diferentes lugares y contextos dentro de cada uno de estos sitios, podemos afirmar entonces que no hubo sectorizaciones estilísticas dentro de los asentamientos o a nivel regional (fig. 8).

En este contexto social y material, las vasijas cerámicas contribuyeron fuertemente en construir el sentido de homogeneidad y semejanza que tenía la vida en los poblados conglomerados. Más allá que la forma de organizar la decoración muestre la relevancia que los principios de dualidad y simetría pudieron tener en la organización y el pensamiento de las comunidades intermedias tardías (tal como estos tuvieron y tienen en la cultura andina), y más allá de lo que estos motivos pudieran significar, las vasijas cerámicas y las representaciones que tenían inscritas en sus superficies contribuían a profundizar el orden material y social que las personas vivían en los poblados conglomerados. Al circular por un asentamiento, visitar vecinos, participar de un ritual fúnebre, e incluso visitar otras comunidades, las personas se topaban una y otra vez con los mismos motivos y una manera muy restringida de inscribirlos en las vasijas. La figura 8 grafica este punto con ejemplos de piezas provenientes de dos sitios separados por $10 \mathrm{~km}$ de distancia y dos contextos diferentes separados por $400 \mathrm{~m}$ dentro de uno de estos sitios. Estos ejemplos claramente muestran que se apeló a los mismos motivos y una misma forma de distribuirlos en la superficie de las vasijas.

Así, no solo la arquitectura permitía una articulación fluida entre los residentes de un asentamiento conglomerado, sino también la iconografía cerámica integraba a los habitantes de estas comunidades, y de la región toda, a través de la reproducción de una iconografía específica y delimitada. La gran redundancia que exhibían las representaciones visuales plasmadas en contenedores cerámicos, en conexión con la arquitectura y los objetos que definían la vida cotidiana en los poblados conglomerados, creaban un fuerte ethos de similitud e interconexión, participando en la creación de una vida social que desalentaba la diferencia y propiciaba la homogeneidad y permeabilidad (los motivos 
Grecas

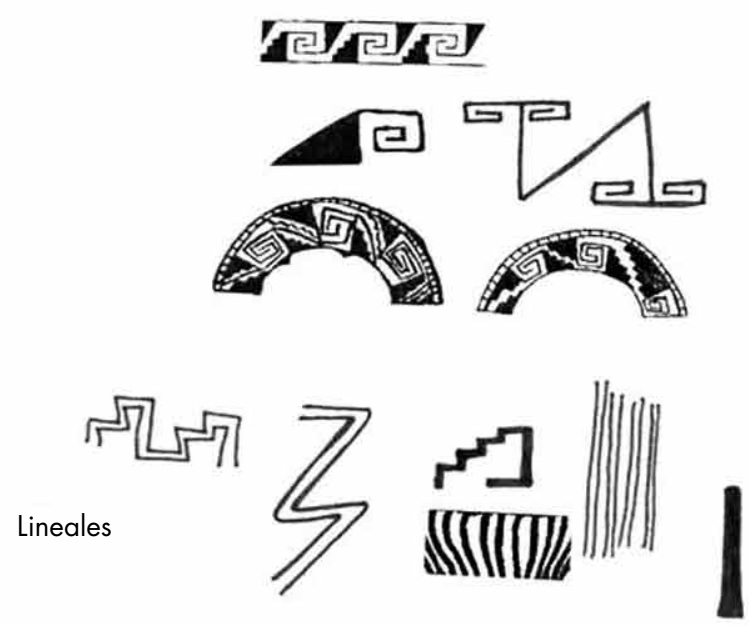

Espirales

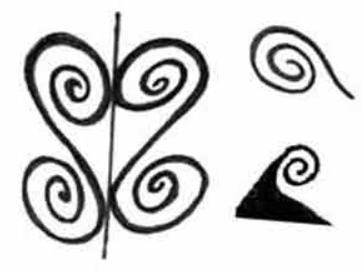

Rostros

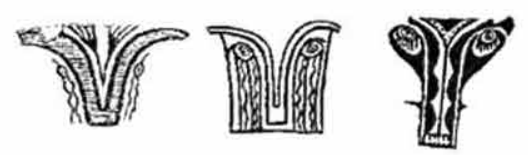

Chevrones

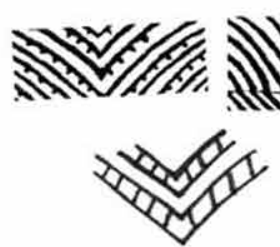

Dameros
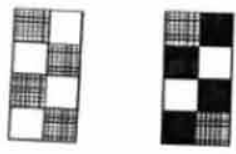

Figura 6. Motivos decorativos cerámicos.

Figure 6. Ceramic decorative motifs.
Serpentiformes
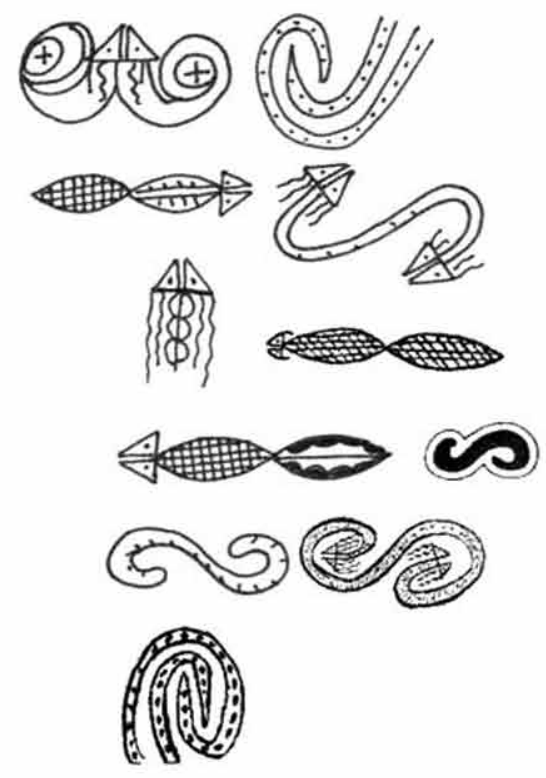

Manos
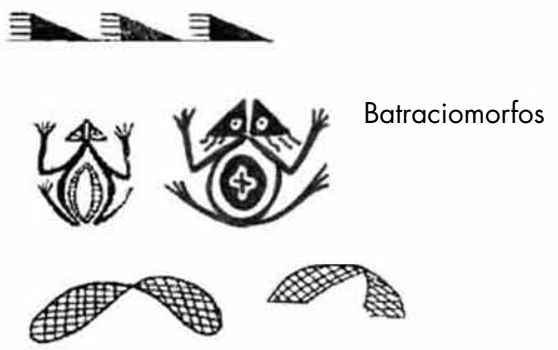

Reticulados

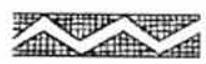

Ornitomorfos

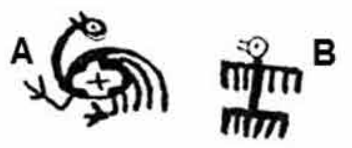

Otros

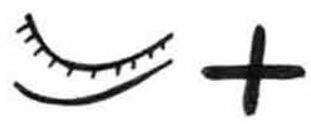




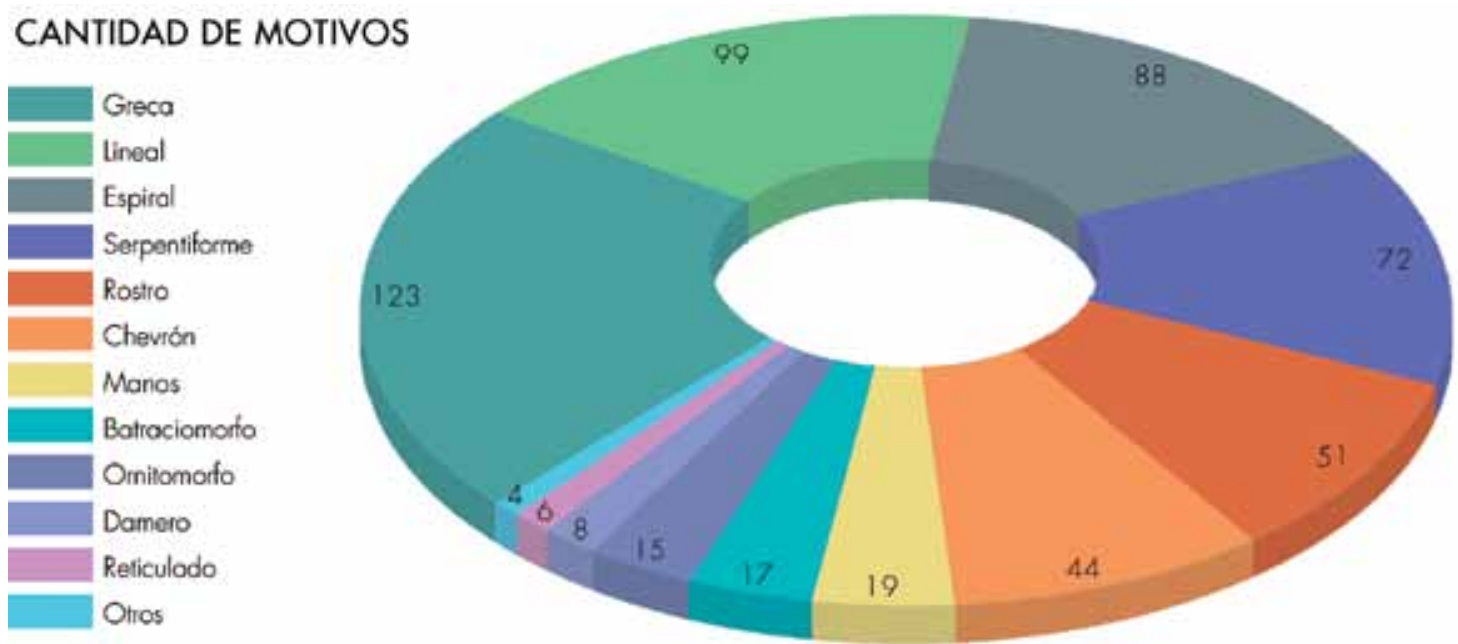

Figura 7. Grupos de motivos cerámicos y cantidades. Figure 7. Ceramic motif groups and quantities.

cruzaban las fronteras entre grupos y familias dentro de una comunidad, las fronteras entre comunidades, así como las de la vida y la muerte). Sumado a esto, y considerando la poca variación decorativa en cuanto a los motivos principales y la estricta organización de los mismos sobre la superficie de las piezas, se puede sostener entonces que en este contexto sociohistórico la creatividad individual se diluía en la tradición. La producción de vasijas decoradas no muestra una intención de las personas por innovar y marcar diferencias con otras familias u otras comunidades, sino, más bien, una búsqueda generalizada por la similitud y la repetición. En conclusión, la producción simbólica plasmada en la mayoría de las vasijas cerámicas decoradas no apuntaba a la ruptura y a la heterogeneidad, a la creatividad y la distinción, sino a la homogeneidad y a la articulación.

Pasemos ahora a explorar las representaciones rupestres. Si bien existen varios sitios de petroglifos en la región, en este trabajo nos limitaremos a un caso particular: el sitio Los Cerrillos (SSalCac 82) (figs. 1 y 9). Elegimos este lugar ya que a partir de su estudio sistemático pudimos determinar que muchos de los grabados allí localizados pertenecen al Período Intermedio Tardío.

Para establecer la cronología de las representaciones rupestres nos hemos basado principalmente en el amplio corpus bibliográfico que ha tratado este tema en el Noroeste Argentino en general y en nuestra región de estudio en particular (Aschero 1999, 2000; Lanza 2000; Hernández Llosas 2001; Martel 2010, entre otros). De acuerdo con estos estudios sistemáticos y de larga data, los escutiformes, los unkus, los antropomorfos T, los antropomorfos alineados o en escenas de combate, los antropomorfos con elementos que marcan jerarquización social (adornos cefálicos y portando distintos objetos), algunos antropomorfos esquemáticos simples, las llamas de diseño esquemático y estandarizado (ya sea aisladas, en grupos, alineadas, alineadas y unidas con sogas), de cuellos rectos y cuerpos angostos, generalmente de dos patas, una sola oreja hacia adelante y cola levantada, los vínculos anecdóticos entre las figuras humanas y las llamas, y las maquetas, serían los motivos principales del Período Intermedio Tardío.

Por nuestra parte, hemos trabajado para dilucidar la cronología de los motivos rupestres del valle Calchaquí Norte de tres maneras:

1) Investigando las figuras que aparecen en los pocos petroglifos que se encuentran directamente asociados con sitios del Intermedio Tardío. Específicamente se estudiaron los petroglifos que aparecen dentro de tres asentamientos: La Banda 1 (SSalCac 28), La Hoyada (SSalCac 144) y SSalCac 176. Encontramos asociados con estos sitios del Intermedio Tardío: círculos y conjuntos de círculos, figuras humanas en actitud de combate, un suri, llamas esquemáticas, un reticulado tipo maqueta, un zigzag y varias figuras que las personas locales describen como un ave volando (fig. 10). Esta última figura se ha encontrado en muchos sitios de la región repetidas veces.

2) Comparando motivos inscritos en objetos recuperados de contexto de excavación de sitios de esta época con aquellos grabados en las rocas. En este caso pudimos comprobar que una figura antropomorfa típica del arte rupestre de nuestra región (fig. 10, antropomorfo $N^{\circ}$ 2) fue también encontrada tallada en sobrerrelieve en una tableta de piedra recuperada en excavación del sitio Tero (SSalCac 14). 
Procedencia: Sitio La Paya (SSalCac 1)

A

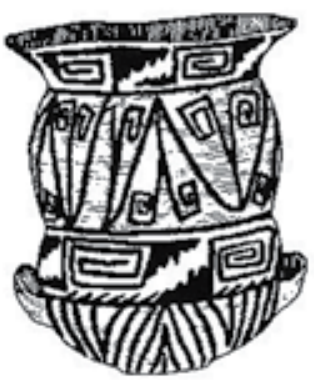

Procedencia: Sitio La Paya (SSalCac 1)

C

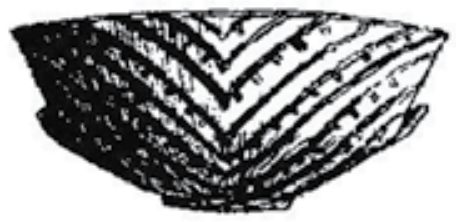

Procedencia: Tumba 105, sector "Necrópolis", Sitio La Paya (SSalCac 1)

E

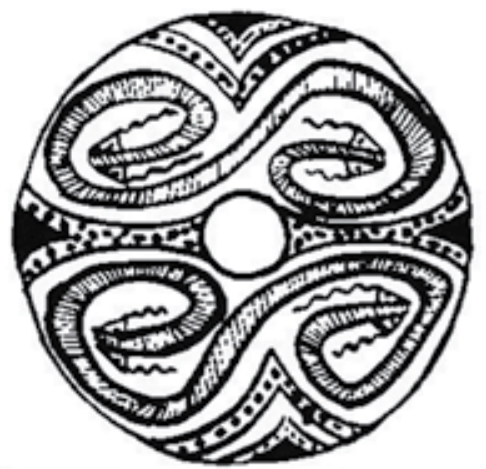

Procedencia: Sitio Tero (SSalCac 14)

B

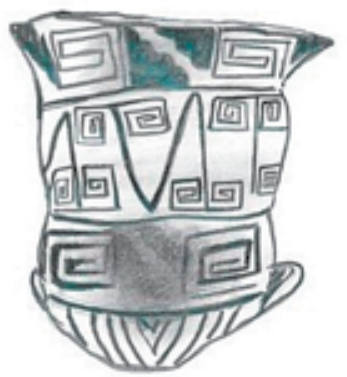

Procedencia: Sitio Tero (SSalCac 14)

D

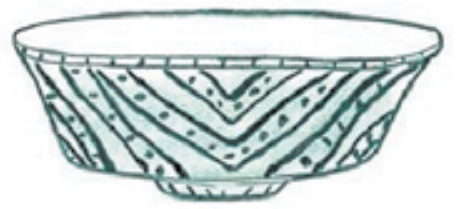

Procedencia: Tumba 195, sector "al otro lado del río La Paya", Sitio La Paya (SSalCac 1)

F

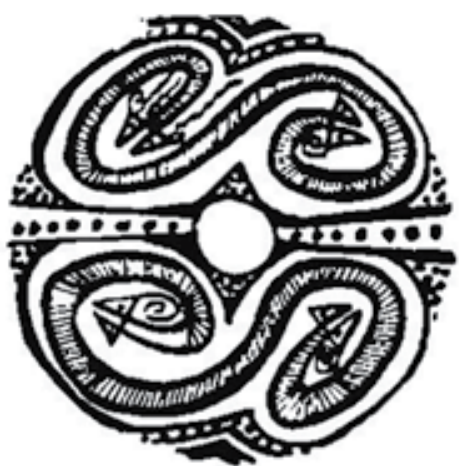

Figura 8. Similitud entre piezas provenientes de distintos sitios y distintos contextos dentro de un mismo sitio. Ejemplos A, C, E y F redibujados de Ambrosetti (1907-1908), ejemplos B y D dibujados por Marina Smith.

Figure 8. Similarity between pieces from different sites, and between pieces from different contexts within the same site. A, $C, E$ and $F$ were redrawn from Ambrosetti (1907-1908); B and D were drawn by Marina Smith.

3) Rastreando petroglifos con motivos escutiformes y antropomorfos $\mathrm{T}$ en sitios de la región (motivos diagnósticos del Período Intermedio Tardío) y registrando con qué otras figuras estaban asociados, siempre y cuando no hubiera superposición y compartiesen el mismo tipo de técnica de producción y pátina. Hemos encontrado motivos escutiformes y antropomorfos T compartiendo paneles con: llamas esquemáticas, llama con cría, círculos, tumiformes, pies humanos, y varias veces conectados con el motivo del "ave volando".
Los Cerrillos es una formación de cerros bajos y redondeados ubicados en el medio del valle Calchaquí (fig. 1). Tiene $8 \mathrm{~km}$ de longitud norte-sur y a ambos lados hemos detectado pequeños morritos, que van de cuatro a $20 \mathrm{~m}$ de altura, y algunos afloramientos rocosos donde se concentraron petroglifos (figs. 11 y 12). Existen en Los Cerrillos 43 morritos y afloramientos rocosos que se presentan como unidades discretas o loci de concentración de representaciones rupestres, separados por espacios sin arte y visualmente conectados. Estos 


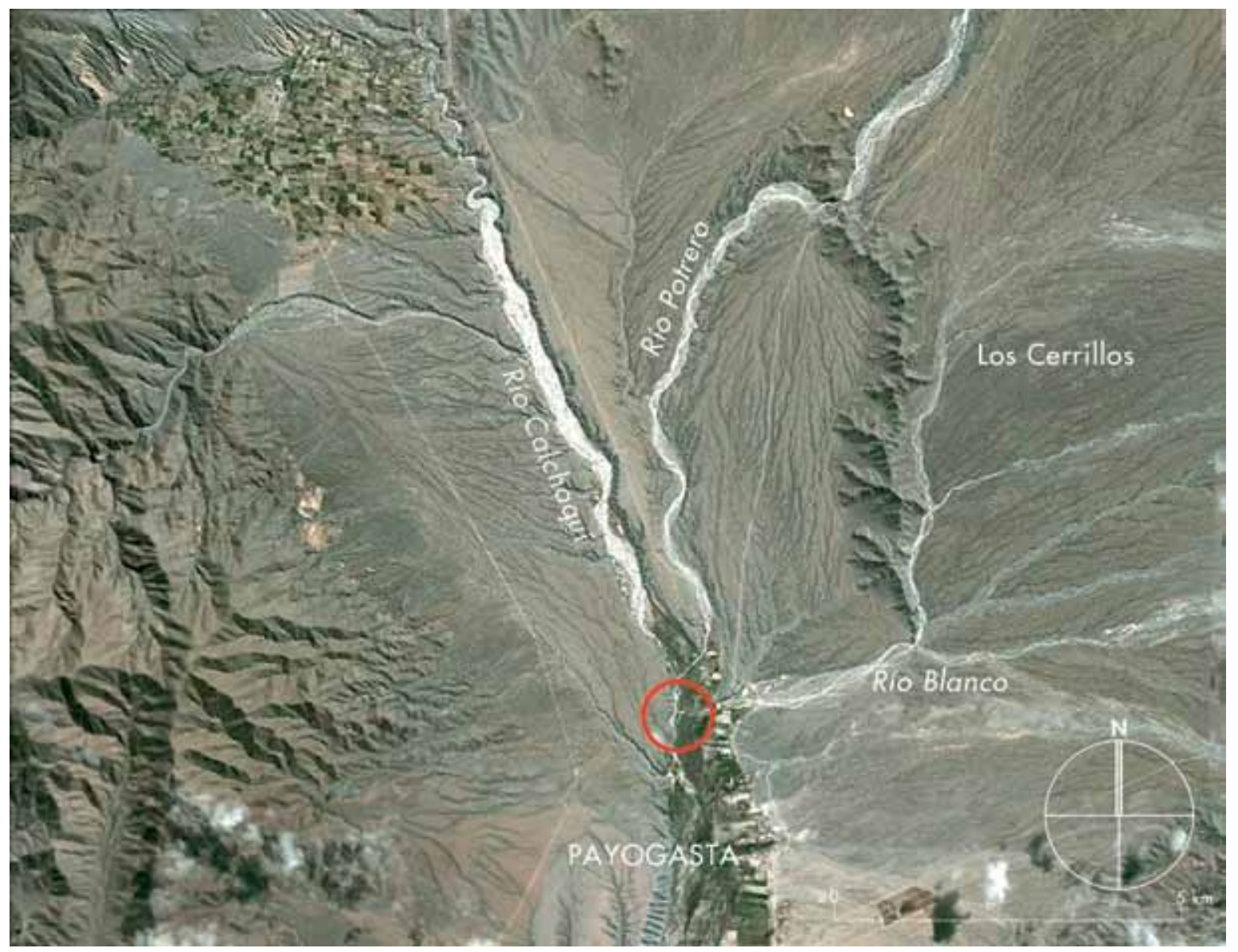

Figura 9. Vista aérea de Los Cerrillos y unión de ríos Calchaquí, Potrero y Blanco.

Figure 9. Aerial view of Los Cerrillos and the confluence of the Calchaqui, Potrero and Blanco rivers.

43 conjuntos presentan un total 839 petroglifos, entre paneles compuestos y petroglifos de un solo motivo. En Los Cerrillos encontramos muchos de los motivos que han sido asignados al Período Intermedio Tardío por diversos investigadores (tal como las llamas estandarizadas y esquemáticas solas, en pares o en grupos -sueltas en la mayoría de los casos, pero en un caso en un corral y en otro en caravana-, relaciones anecdóticas entre llamas y figuras humanas, escutiformes y maquetas, ver figs. 10, 13,14 y 15), así como aquellos que pudimos determinar nosotros a partir de asociaciones con sitios arqueológicos del Intermedio Tardío, con objetos recuperados de estos sitios y con asociaciones con escutiformes y antropomorfos $\mathrm{T}$ (círculos aislados y en grupos, zigzags, tumiformes, maquetas, llamas esquemáticas y estandarizadas, llamas con crías, antropomorfo $\mathrm{N}^{\circ} 2$, pies humanos y el motivo del "ave volando", ver figs. 10 y 15).

Por su forma y localización, Los Cerrillos constituye un rasgo natural altamente llamativo dentro del paisaje norcalchaquí (fig. 9). Allí, el valle principal se une con varias quebradas que comunican al valle Calchaquí con regiones aledañas (como la puna al oeste, la Quebrada del Toro al noreste y las tierras bajas y boscosas del este). Además, la morfología del valle se transforma en este punto, pasando de ser un valle estrecho, de $5 \mathrm{~km}$ de ancho, a un amplio valle de más de $25 \mathrm{~km}$ de ancho (fig. 1). Sumado a esto, Los Cerrillos está directamente asociado con la unión de tres ríos (Calchaquí, Potrero y Blanco). Para la cosmología andina estos lugares de intersección son de gran importancia simbólica, muchas veces definidos como taypi o chawpi, lugares de convergencia, el centro en donde se unen y median las esferas sociales y simbólicas -opuestas y complementarias- (Bouysse-Cassagne 1987; Ossio 1996; Allen 1997; Wachtel 2001: 64), o como tinku o lugares de encuentro (Allen 1988: 65).

Hemos encontrado que en Los Cerrillos se producían una serie de rupturas con otros lugares dentro del paisaje del Período Intermedio Tardío del valle Calchaquí Norte. En Los Cerrillos se alteraba principalmente la esfera de la vida cotidiana y doméstica que se experimentaba en los poblados conglomerados. Se trataba de un lugar creado como el negativo de esta experiencia. 


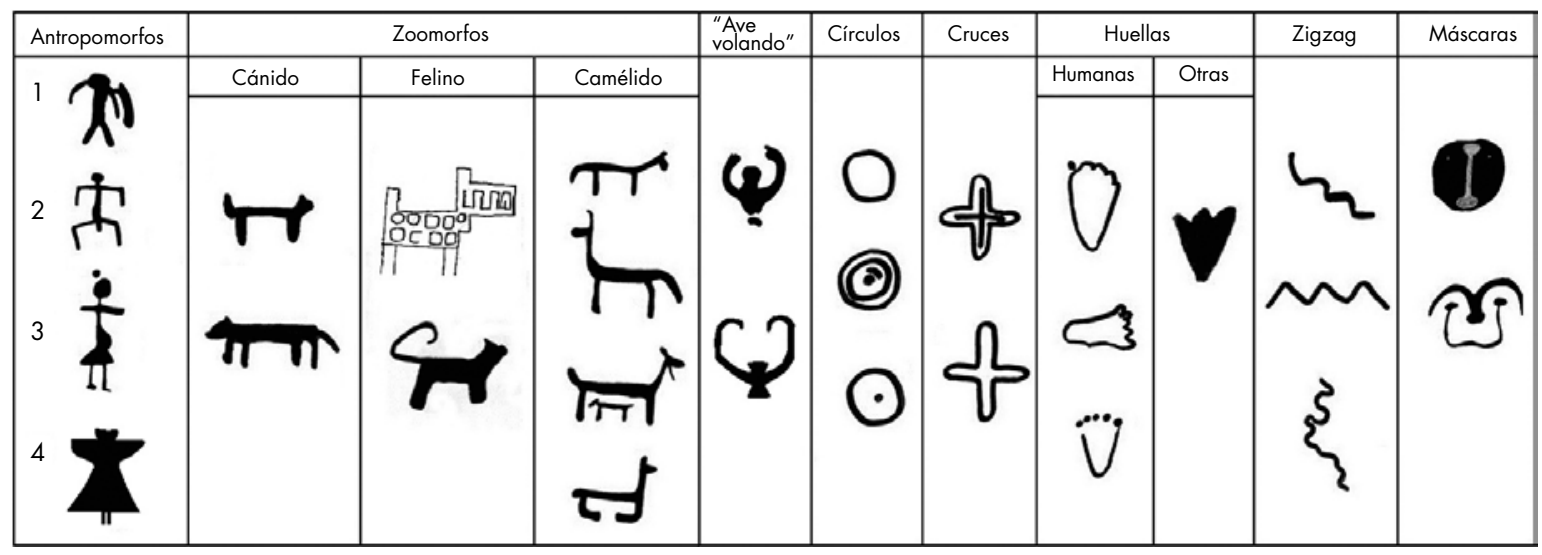

Figura 10. Principales motivos de Los Cerrillos.

Figure 10. Main motifs from Los Cerrillos.

La primera ruptura fue con el mundo material que se vivía en los poblados, el cual está básicamente ausente en Los Cerrillos (como en general sucede en los sitios de arte rupestre de la región). Salvo 10 pequeñas estructuras de piedra, circulares y superficiales, de menos de dos metros de diámetro cada una (que no son tumbas), dispersas en un área de $16 \mathrm{~km}^{2}$, no hubo inversión en arquitectura en este lugar. Es decir, no fue un espacio modificado a través de la construcción de edificaciones. Asimismo, están llamativamente ausentes los restos cerámicos (elemento ubicuo y sello distintivo de la vida en los poblados y de la esfera funeraria). No hay evidencias de actividades de producción de artefactos asociadas con Los Cerrillos, tampoco está el sitio relacionado con estructuras funerarias o de producción agrícola.

La segunda ruptura que se nota en Los Cerrillos es de tipo simbólica (figs. 6 y 10). El motivo decorativo abstracto más común en la cerámica, la greca, está completamente ausente en Los Cerrillos, y en 839 petroglifos solo se han encontrado seis ejemplos de espirales y uno de chevrón, ambas figuras altamente frecuentes en la cerámica. El motivo de manos está ausente en el lugar y, si bien las representaciones de serpientes son frecuentes en las vasijas cerámicas, estas no aparecen en las rocas de Los Cerrillos, al menos tal como fueron diseñadas en las ollas. En el caso de los grabados en roca hay líneas zigzag que podrían quizá estar representando el cuerpo de una serpiente. No obstante, estos dibujos no explicitan características diagnósticas como cabeza, ojos, boca o lengua, como sí aparecen en la cerámica. Así, ninguna de estas figuras se asemeja a las dibujadas en las vasijas. Otras dos figuras zoomorfas que se presentan en la cerámica y no en las rocas de Los Cerrillos son los batracios y los ornitomorfos, aunque los ornitomorfos de tipo A o suris fueron encontrados en sitios de petroglifos cercanos a Los Cerrillos.
Se da también la situación inversa. Varias de las figuras que aparecen comúnmente en Los Cerrillos y en otros sitios de arte rupestre no están presentes en la cerámica, tales como círculos, conjuntos de círculos y

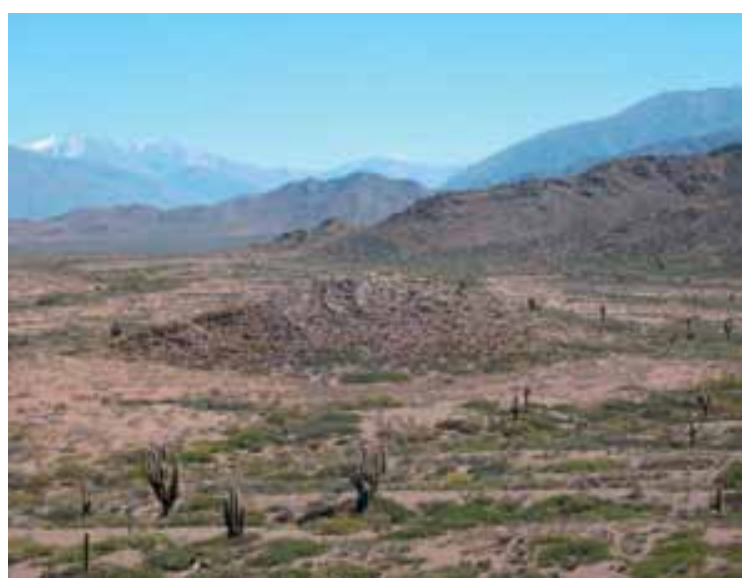

Figura 11. Los Cerrillos, morrito con petroglifos.

Figure 11. Los Cerrillos, outcrop with petroglyphs.

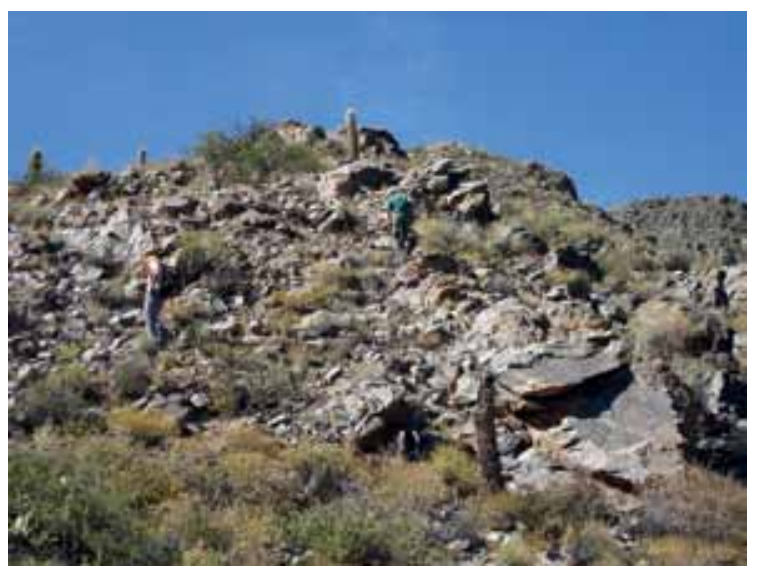

Figura 12. Los Cerrillos, afloramiento rocoso con petroglifos. Figure 12. Los Cerrillos, rocky outcrop with petroglyphs. 
círculos concéntricos. En cuanto a las representaciones figurativas, no fueron plasmados en la cerámica motivos antropomorfos esquemáticos de cuerpo entero ni huellas de pies humanos, dibujos distintivos del arte rupestre. Los escutiformes, presentes en la cerámica santamariana de otras regiones pero no en la del valle Calchaquí Norte, aparecen en el arte rupestre de Los Cerrillos así como en otros sitios de la región (fig. 10, antropomorfo 4). El motivo zoomorfo más frecuente en la roca es el camélido, el cual jamás fue plasmado en la cerámica, como así tampoco los cánidos. No aparece en las vasijas el motivo del "ave volando" o el "ave volando" antropomorfizada, elementos característicos del arte rupestre del Período Intermedio Tardío del valle Calchaquí Norte.

Hay figuras que, sin embargo, pertenecieron a ambos campos expresivos, tal como los motivos lineales, zigzags, reticulados, cruces, rostros antropomorfizados (escasos en Los Cerrillos [n=3] y mucho más abundantes en la cerámica $[n=51]$ ) y las representaciones de felinos (aunque en baja proporción en ambos soportes y presentes en la cerámica en forma modelada en piezas pequeñas de bordes invertidos).
Podemos concluir entonces que una serie de motivos parecerían no haber cruzado las fronteras materiales y no haber pertenecido a ciertos lugares, objetos y ámbitos de interacción. Mientras que grecas, chevrones, espirales, motivos de manos, serpientes, batracios y ornitomorfos nunca o muy raramente aparecen grabados en las rocas de Los Cerrillos, así como en otros sitios de arte rupestre de la región; camélidos, figuras humanas esquemáticas de cuerpo completo, escutiformes, pies humanos, el motivo del "ave volando", círculos, círculos concéntricos y conjuntos de círculos no fueron dibujados sobre la superficie de las ollas.

En tercer lugar, la rigidez observada en la estructura del diseño de las vasijas (donde dualidad y simetría refleja son los principios que organizan la distribución de los motivos en la superficie de prácticamente todas las piezas) no tiene lugar en los paneles de grabados rupestres, en los conjuntos o concentraciones de petroglifos y en Los Cerrillos como unidad topográfica.

En todos los casos de petroglifos compuestos del sitio se trazaron ejes a fin de detectar patrones de dualidad y simetría en la distribución de los motivos (figs. 13 y 14). Solamente en cinco casos $(0,59 \%)$ se constató cierto

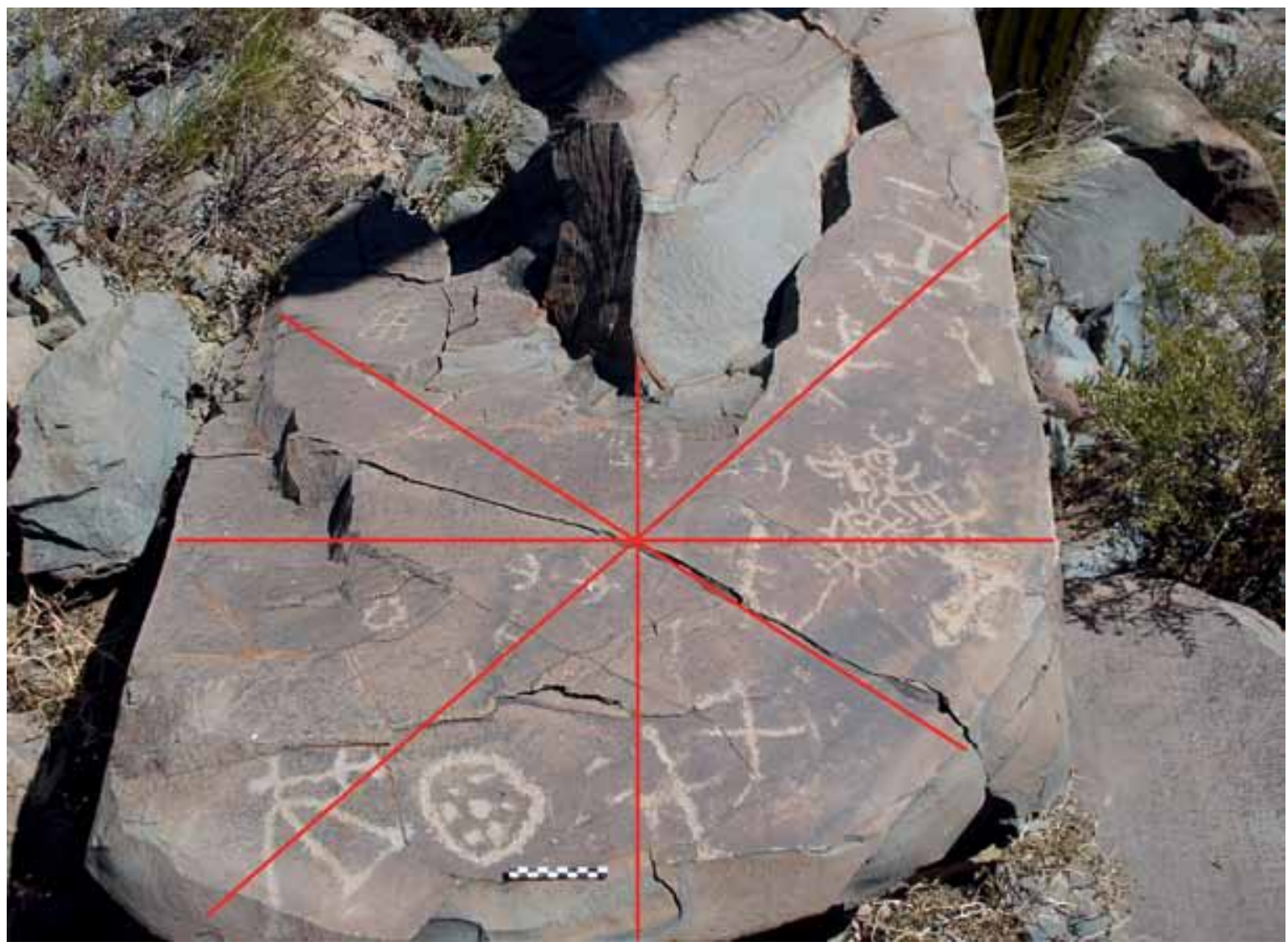

Figura 13. Ejemplo de panel del sitio Los Cerrillos analizado en búsqueda de divisiones duales y simetrías.

Figure 13. Sample panel from Los Cerrillos site, analyzed in regard to dualities and symmetries. 


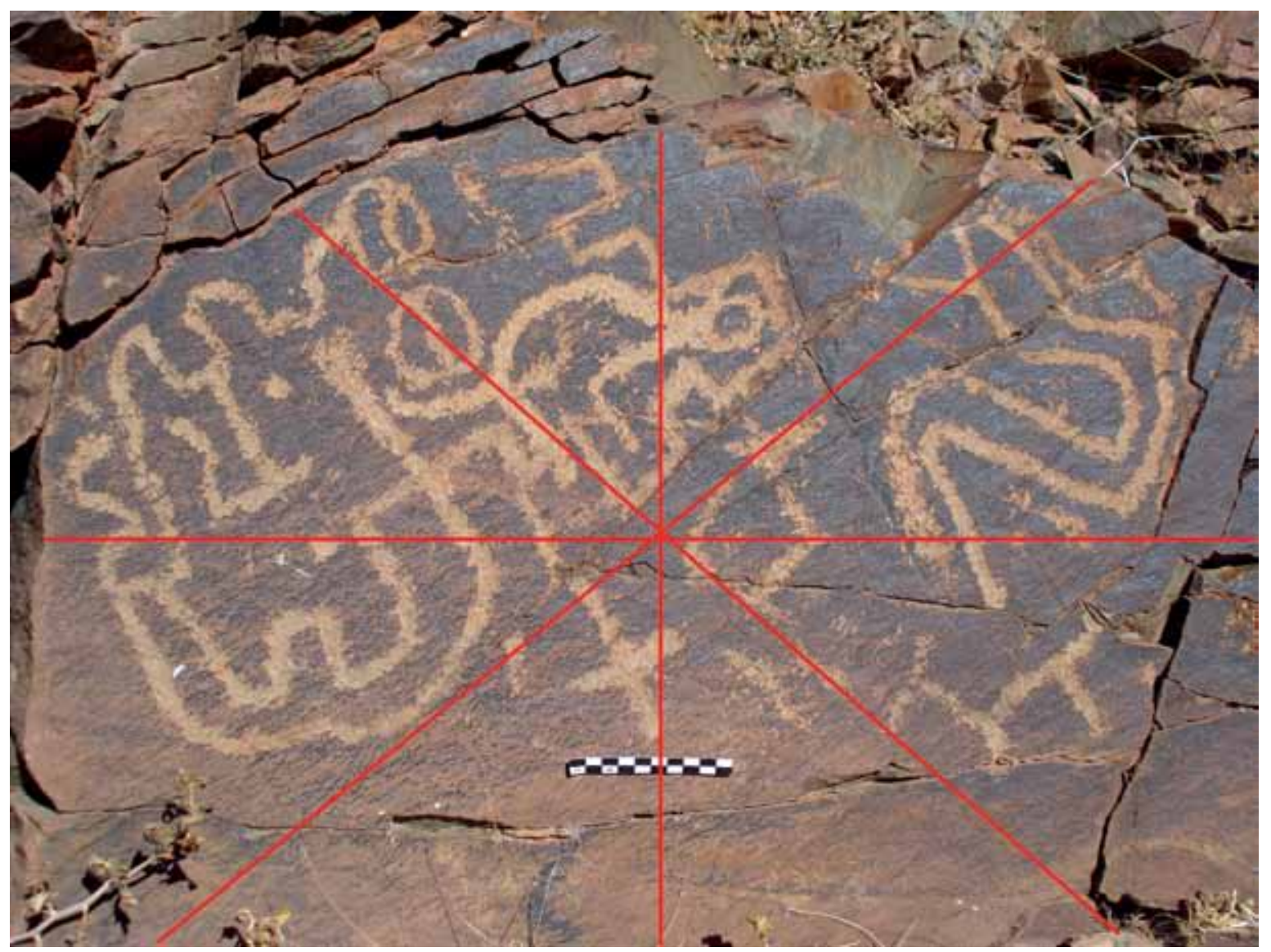

Figura 14. Ejemplo de panel del sitio Los Cerrillos analizado en búsqueda de divisiones duales y simetrías. Figure 14. Sample panel from Los Cerrillos site, analyzed in regard to dualities and symmetries.

nivel de simetría de tipo refleja en el diseño, aunque no se han detectado al momento reflexión de tipo desplazada y rotación en la muestra. Su bajo porcentaje lleva a pensar en una situación azarosa más que en una acción intencional.

Analizamos también la distribución de los motivos en nueve loci o concentraciones de petroglifos por considerar a estas (ya sea morritos o afloramientos rocosos) como unidades decorativas discretas. Buscamos determinar si existía un eje que dividiera cada una de estas nueve concentraciones o grupos de petroglifos en dos mitades simétricas. De esta manera, consideramos los ejes norte-sur, este-oeste, noroeste-sureste y norestesuroeste, no pudiéndose detectar este tipo de patrón (fig. 16). Fue también observada la distribución de los petroglifos y sus motivos en relación con la topografía, y en este caso tampoco fue posible detectar una clara división en dos partes que se reflejen entre sí.

Por último, se examinó el eje norte-sur que conforma Los Cerrillos como unidad topográfica, comparándose los petroglifos del lado este con los del oeste, sin hallar evidencia de una distribución simétrica refleja de las figuras.

Cuarto, si bien las piezas cerámicas se decoraron apelando a los mismos diseños distribuidos de manera similar (fig. 8), los 43 loci de arte rupestre de Los Cerrillos son distintos entre sí. En este mismo sentido, los paneles compuestos por varios motivos conformando escenas también presentan destacadas diferencias entre sí (tal como los de las figs. 13 y 14). Así, la homogeneidad presente en la producción simbólica en la cerámica se transforma en una marcada variabilidad en el arte rupestre.

Por último, el análisis de las figuras humanas $(\mathrm{n}=110)$ nos ha indicado otra ruptura con respecto a la vida en los poblados conglomerados. En primer lugar, es importante destacar que estas representaciones no expresan jerarquización social y diferencias de estatus entre los personajes dibujados (cf. Aschero 1999; Hernández Llosas 2001). No hay representaciones humanas portando cetros o con tocados especiales, o personajes centrales y de gran tamaño asociados con figuras humanas menores y subordinadas. Tampoco aparecen escenas de combates 


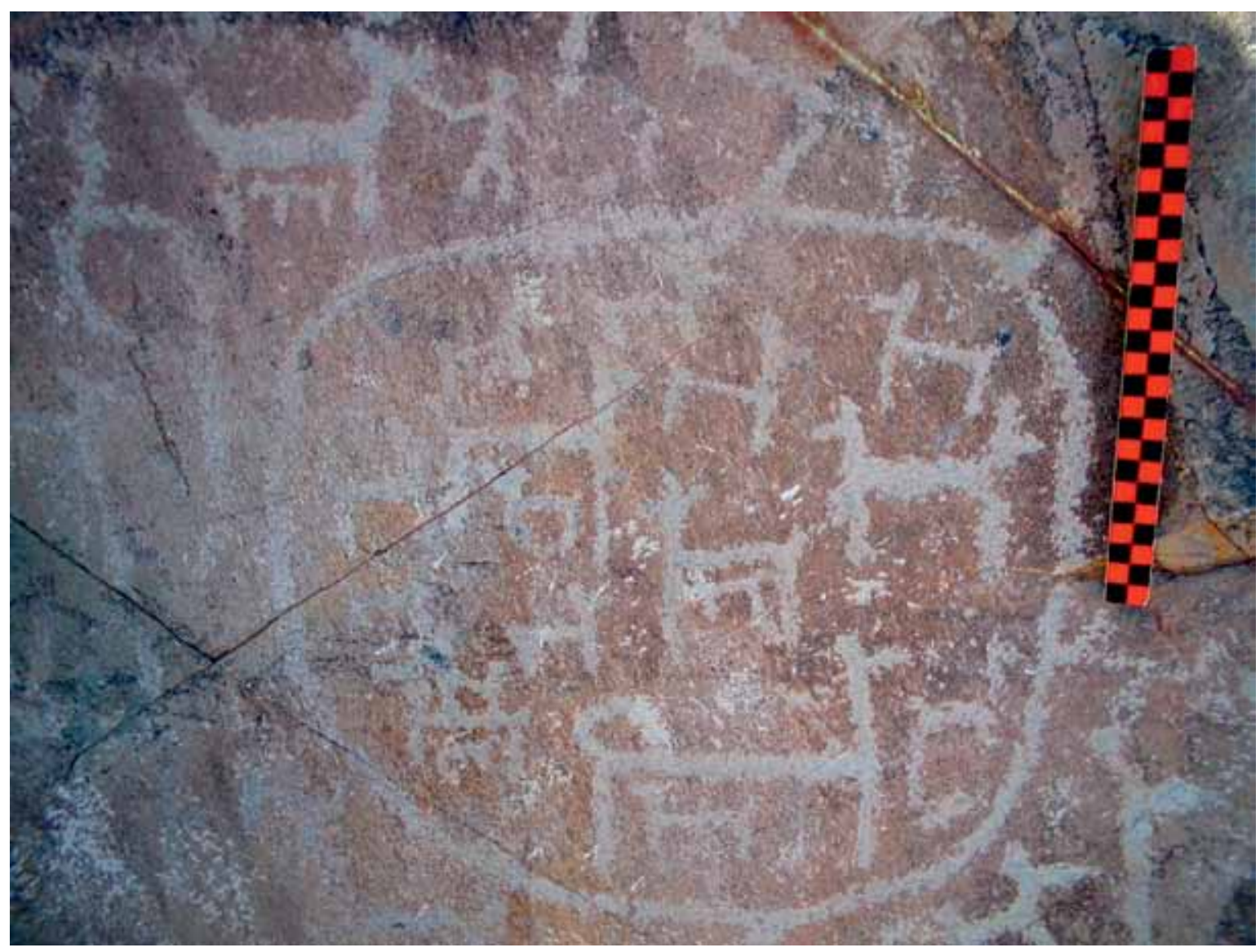

Figura 15. Camélidos hembras con sus crías, camélidos en corral y relaciones anecdóticas entre camélidos y figuras humanas. Figure 15. Female camelids with offspring, camelids in a corral, and anecdotal relations between camelids and buman figures.

entre personajes (aunque estas se han encontrado en otros sitios de la región). La mayoría de las representaciones humanas en Los Cerrillos son, por el contrario, figuras esquemáticas simples, vistas de frente en todos salvo un caso (figs. 10 y 17).

De las 110 figuras antropomorfas, 30 tienen rasgos sexuales masculinos (falo), una tiene lo que parecerían ser testículos y falo y solo una cuenta con rasgos femeninos secundarios (vientre abultado indicando un posible embarazo) (fig. 10, antropomorfo $\mathrm{N}^{\circ}$ 3). Las otras 78 representaciones no tienen rasgos sexuales de ningún tipo.

Salvo el caso antes mencionado, no parece haber figuras que destaquen rasgos femeninos en cuanto a atributos sexuales, reproductivos o de performance corporal. Exceptuando este caso, no hemos encontrado claras representaciones de cuerpos femeninos, sino que lo femenino pudo haber estado representado por las llamas preñadas o con sus crías (figs. 15 y 18). Así, la mujer parece haber sido ocultada, o quizá transformada, en estos contextos. En Los Cerrillos se construyó un discurso de invisibilidad en el cual el género femenino fue subrepresentado. El género masculino ha sido mayoritariamente representado a partir de sus caracteres sexuales primarios resaltando su sexualidad activa, cuando en el caso del género femenino las representaciones rupestres de Los Cerrillos produjeron una cancelación de su sexualidad a través de la no representación de sus órganos genitales. Así, la construcción del orden simbólico corporal femenino fue cercenada a través de una narrativa de ocultamiento. En este sentido, en Los Cerrillos se quiebra, al menos a nivel de género, el principio de homogeneidad social que la materialidad de los poblados conglomerados creaba.

Parte del discurso que ofrece el arte rupestre de este sitio, y que no se ha detectado aún en la cultura material y las representaciones presentes dentro de los poblados, es de distinción entre géneros; en la cual un género es resaltado y el otro escondido. La etnohistoria y etnografía andina han destacado la centralidad del género como principio estructurante de la organización social, el cosmos y el paisaje andino, y la complementariedad masculino/ 
femenina, especialmente en la esfera del matrimonio y la comunidad (Isbell 1976; Allen 1988; Wachtel 2001: 537; Van Vleet 2008). Dentro del orden social, simbólico y material del mundo andino, se ha demostrado que la casa constituye el ámbito de la mujer (Arnold et al. 1992; Allen 1988; Van Vleet 2008). Teniendo en cuenta esto y el tipo de representaciones encontradas, es posible pensar a nivel de hipótesis que en contraposición con la esfera del poblado y la casa, Los Cerrillos (y quizá los otros sitios de arte rupestre) se constituyó como un espacio de expresión (¿y reunión?) masculina que se contraponía con el ámbito femenino del hogar.

En conclusión, Los Cerrillos fue constituido como un lugar particular y distintivo del paisaje del Período Intermedio Tardío del valle Calchaquí Norte, conformado por un orden material que transformaba y negaba aquel vivido en la vida cotidiana de los poblados conglomerados. En el área de Los Cerrillos, y a diferencia de los poblados conglomerados, prácticamente no había arquitectura, no se instalaron viviendas, no se producían objetos, no se enterraba a los difuntos, no había una asociación directa con áreas agrícolas y no se decoraban las rocas de la misma manera como se decoraban las vasijas. Dentro de la trama que creaba el paisaje, Los Cerrillos fue un espacio liminal, de transformación y ruptura con la

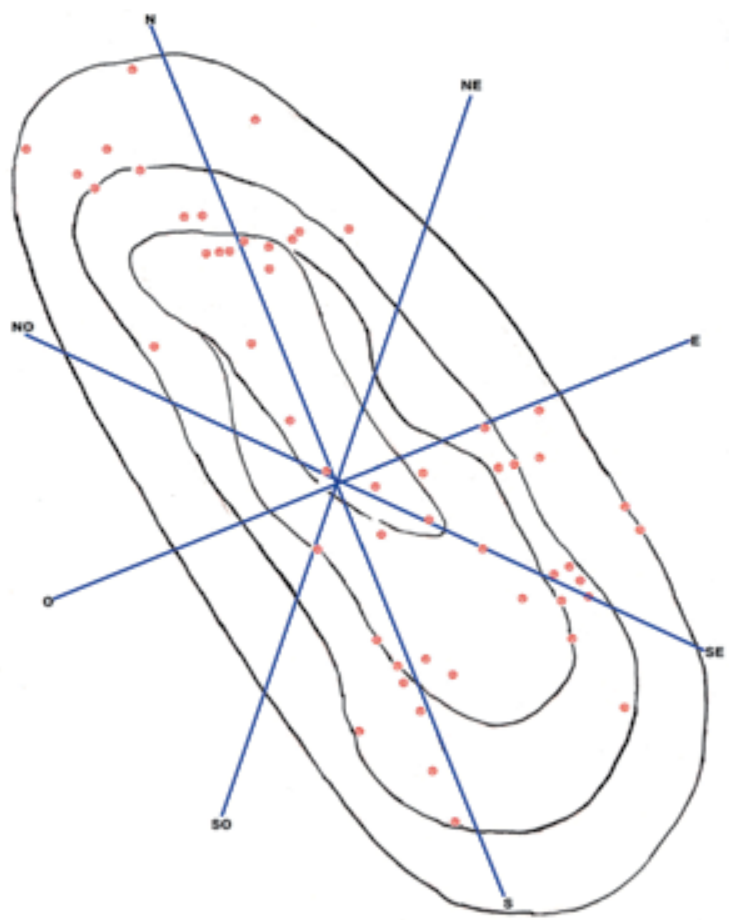

Figura 16. Ejemplo de análisis de la distribución de los petroglifos (círculos) y motivos en búsqueda de patrones de dualidad y simetría. Morrito AD.

Figure 16. Analysis of petroglyph and motif distribution (circles) in regard to patterns of duality and symmetry. Morrito AD. esfera cotidiana y doméstica. Considerando que se ha argumentado que los rituales andinos son inversiones del orden establecido (Greenway 1998: 159), es posible pensar a Los Cerrillos como un espacio ritual que invertía el orden experimentado en la vida diaria.

\section{CONCLUSIÓN}

Este ejemplo nos muestra que solo lograremos un entendimiento profundo y completo de las representaciones visuales cuando estas no sean abordadas como simples imágenes desconectadas del orden material en donde se encuentran insertas, sino que sean enhebradas con lugares y paisajes, objetos, rasgos naturales, sentidos, relaciones sociales, prácticas y experiencias. Solo así lograremos tejer una trama continua en la cual la evidencia arqueológica entre en un diálogo en el cual se diluyan las separaciones analíticas que realizamos en el presente para dar lugar al entendimiento de la vida social en el pasado.

En este trabajo empleamos a las representaciones visuales como puerta de entrada al pasado pero no a fin de entender a estas en sí mismas sino para reconstruir la naturaleza de los lugares en donde estaban presentes, el orden material que allí se experimentaba, el tipo de interacciones que se producían entre personas y personas
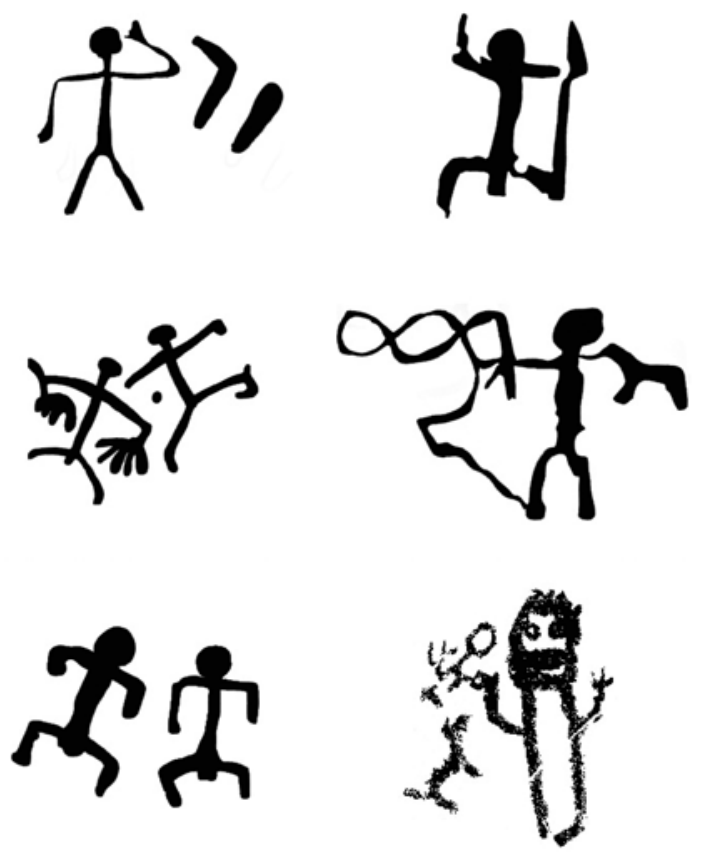

Figura 17. Ejemplos de figuras antropomorfas, sitio Los Cerrillos. Figure 17. Examples of buman figures, Los Cerrillos site. 


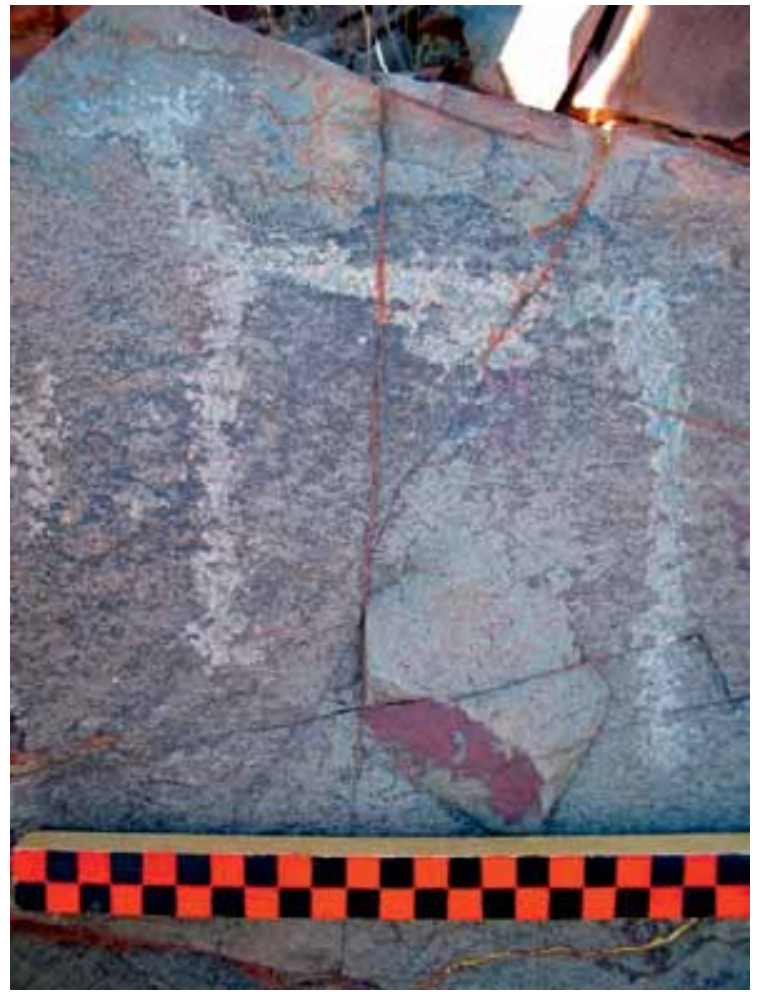

Figura 18. Camélido hembra preñada. Figure 18. Pregnant female camelid.

y objetos, y el sentido de lugar que estas representaciones ayudaban a construir. Así, vimos cómo las figuras que se pintaron en las vasijas cerámicas participaban y eran activas en la producción de un contexto social y material muy distinto de aquel en el que estaban insertos los grabados rupestres. En el Período Intermedio Tardío del norte del valle Calchaquí, el poblado, la arquitectura, las casas, el ámbito de la mujer, las tumbas, los utensilios diarios, la vida cotidiana y pedestre y la cerámica decorada conformaban un dominio marcadamente distinto, en cuanto a prácticas, tipo de interacciones y sentidos, del dominio extraordinario de los sitios de petroglifos como Los Cerrillos.

\section{NOTAS}

${ }^{1}$ Esta investigación fue financiada a partir de un subsidio otorgado por Wenner-Gren Foundation for Anthropological Research, International Collaborative Research Grant.

${ }^{2}$ Es interesante notar que los petroglifos no solamente suelen estar separados de los sitios de habitación, sino también de las áreas agrícolas. Un caso distintivo es el sitio Las Pailas, con canchones delimitados por muros de piedra que abarcan algo más de 400 ha. A pesar de la gran cantidad de rocas potencialmente grabables en este amplio sector agrícola, no se han observado expresiones plásticas sobre dichas rocas.
${ }^{3}$ Existen interesantes trabajos contemporáneos que proponen otras interpretaciones (alternativas en algunos casos y complementarias en otros) sobre la iconografía de las vasijas santamarianas que por falta de espacio no exploraremos en este artículo, pero que el lector puede consultar para comparar (Velandia 2005; Nastri 2005-2006, 2008; Nastri et al. 2009).

${ }^{4}$ Los sitios de donde se recuperaron estas vasijas son: SSalCac $1,4,5,8,10,14,16,17,23,44,79,133$, Punta de Agua y Rancagua. Existe una importante colección de vasijas cerámicas proveniente de la excavación de tumbas del sitio La Paya (SSalCac 1) que se encuentra depositada en el Museo Etnográfico de Buenos Aires. Si bien esta colección no ha sido aún analizada, incluimos algunos ejemplos de vasijas provenientes de La Paya publicados por Ambrosetti (1907-1908) a fin de graficar algunos de los puntos que buscamos hacer en el artículo.

${ }^{5}$ Es importante aclarar que si bien a las ollas de cuellos largos se las denomina comúnmente urnas por haberse encontrado conteniendo entierros de infantes, abundante evidencia indica que esta no fue su única función y que los infantes no eran solo enterrados en este tipo de ollas decoradas (Díaz 1978-84, 1981). En nuestras propias investigaciones, y a través del análisis de ácidos grasos provenientes de una de estas vasijas, pudimos comprobar que la misma también había sido empleada para almacenar alimentos (Amuedo 2010).

\section{REFERENCIAS}

AcuTo, F. A., 2007. Fragmentación vs. integración comunal: Repensando el Período Tardío del Noroeste Argentino. Estudios Atacameños 34: 71-95.

Acuto, F. A.; C. Amuedo, M. Kergaravat, A. Ferrari, L. Gamarra \& A. L. Goldín, 2008. Experiencias subjetivas en las aldeas prehispánicas del valle Calchaquí Norte: Arqueología de la vida cotidiana, prácticas y relaciones sociales durante el Período Prehispánico Tardío. En Arqueología del extremo sur del continente americano. Resultados de nuevos proyectos, L. A. Borrero \& N. V. Franco, Eds., pp. 11-54. Buenos Aires: CONICET-IMHICIHU.

Acuto, F. A.; M. Kergaravat \& C. Amuedo, 2011. Experiencia de la muerte y la representación de las personas en las prácticas funerarias del valle Calchaquí Norte. Comechingonia, Revista de Antropología 14: 23-54.

AlLEN, C., 1988. The bold life has: coca and cultural identity in an Andean community. Washington D. C.: Smithsonian Institution Press.

— 1997. Enfolding oppositions: narrative and structure in Quechua story. Journal of Steward Anthropological Society 25 (1-2): 8-26.

AMBrosetTI, J. B., 1907-1908. Exploraciones arqueológicas en la ciudad prebistórica de La Paya (valle Calchaquí, pcia. de Salta). Buenos Aires: Editorial de la Facultad de Filosofía y Letras, Universidad de Buenos Aires.

Amuedo, C., 2010. La muerte de niños y su tejido de materialidad. Prácticas, representaciones y categorías construidas en las tumbas de infantes en vasijas, Período Tardío (900-1470 DC), valle Calchaquí Norte. Tesis de Licenciatura, Facultad de Filosofía y Letras, Universidad de Buenos Aires.

ARNOLD, D.; D. JIMÉNEZ \& J. YAPITA, 1992. Hacia un orden andino de las cosas: tres pistas de los Andes meridionales. La Paz: Hisbol, IlCA.

Aschero, C., 1999. El arte rupestre del desierto puneño y el Noroeste Argentino. En Arte Rupestre en los Andes de Capricornio, J. Berenguer \& F. Gallardo, Eds., pp. 97-135. Santiago: Museo Chileno de Arte Precolombino.

-2000. Figuras humanas, camélidos y espacios en la interacción circumpuneña. En Arte en las rocas. Arte rupestre, menbires y piedras de colores en la Argentina, M. Podestá \& M. de 
Hoyos, Eds., pp. 17-44. Buenos Aires: Sociedad Argentina de Antropología.

Battaglia, D., 1990. On the bones of the serpent: person, memory and mortality in Sabarl Island society. Chicago: University of Chicago Press.

Bouysse Cassagne, T., 1987. La identidad Aymara. La Paz: HisbolInstituto Francés de Estudios Andinos.

DíAz, P. P., 1978-1984 Ms. Diario de la excavación realizada en el sitio Tero SSalCac 14. Informe depositado en el Museo Arqueológico de Cachi.

1981 Ms. Diario de excavación realizada en el sitio La Paya SSalCac 1. Informe depositado en el Museo Arqueológico de Cachi.

GeLl, A., 1995. The language of the forest: landscape and phonological iconism in Umeda. En The Anthropology of landscape. Perspectives on place and space, E. Hirsch \& M. O'Hanlon, Eds., pp. 232-254. Oxford: Clarendon Press.

GIFFORD, C., 2003. Local matters: encountering the imperial Inkas in the South Andes. Tesis doctoral, Columbia University, New York.

GrEenwAY, C., 1998. Objectified selves: an analysis of medicines in Andean sacrificial healing. Medical Anthropology Quarterly 12 (2): $147-167$.

IsBELL, B. J., 1976. La otra mitad esencial: Un estudio de complementariedad sexual andina. Estudios Andinos 5 (1): 37-56.

Hernández Llosas, M., 2001. Arte rupestre del Noroeste Argentino. Orígenes y contexto de producción. En Historia Argentina Prehispánica, Tomo I, E. Berberián \& A. Nielsen, Eds., pp. 389446. Córdoba: Editorial Brujas.

INGOLD, T., 2000. The perception of environment. Essays on livelibood, dwelling and skill. London and New York: Routledge.

LANZA, M., 2000. Análisis estilístico del arte rupestre del valle Calchaquí Norte, Salta. En Arte en las rocas. Arte rupestre, menhires y piedras de colores en Argentina, M. Podestá \& M. de Hoyos, Eds., pp. 63-71. Buenos Aires: Sociedad Argentina de Antropología.
Martel, A., 2010. Arte rupestre de pastores y caravaneros estudio contextual de las representaciones rupestres durante el período agroalfarero Tardío (900-1480 DC) en el Noroeste Argentino. Tesis de doctorado, Facultad de Filosofía y Letras, Universidad de Buenos Aires.

MiLler, D., 1987. Material culture and mass consumption. Oxford: Basil Blackwell.

— 2005. Materiality: an introduction. En Materiality, D. Miller, Ed., pp. 1-50. Durham: Duke University Press.

NASTRI, J., 2005-2006. El simbolismo en la cerámica de las sociedades tardías de los valles calchaquíes (siglos XI a xvI). Arqueología 13: $253-261$.

_ 2008. La figura de las largas cejas de la iconografía santamariana. Chamanismo, sacrificio y cosmovisión calchaquí. Boletín del Museo Chileno de Arte Precolombino 13 (1): 9-34.

Nastri, J.; L. Stern Gelman \& L. Tulissi, 2009. Símbolos de poder en el contexto de una sociedad pre-estatal: indicios en el arte mortuorio calchaquí. En Parentesco, patronazgo y Estado en las sociedades antiguas, M. Campagno, Ed., pp. 297-340. Buenos Aires: Editorial de la Facultad de Filosofía y Letras, Universidad de Buenos Aires.

Ossio, J. M., 1996. Symmetry and asymmetry in Andean society. Journal of Steward Anthropological Society 24 (1-2): 231-48.

Strathern, M., 1988. The gender of the gift. Problems with women and problems with society in Melanesia. Berkeley/Los Angeles: University of California Press.

Thomas, J., 2004. Archaeology and Modernity. Londres: Routledge.

VAN VLEET, K. E., 2008. Performing kinship. Narrative, gender, and the intimacies of power in the Andes. Austin: University of Texas Press.

VELANDiA, C. A., 2005. Iconografía funeraria en la cultura arqueológica de Santa María, Argentina. Olavarría: Inculpa.

WaChTEL, N., 2001. El regreso de los antepasados. Los indios urus de Bolivia, del siglo Xx al XVI. México, D. F.: Fondo de Cultura Económica. 